\title{
Discovery Program: InTEgRating Biomedical ENGINEERING GRADUATE INSTRUCTORS WiTH High SCHOOL STEM Curriculum
}

\author{
Locke Davenport Huyer, Genevieve Conant, Cindy V. Bui*, Ben G. Kinsella*, Andrea Vegh*, Sherif Ramadan, \\ Brittany Lauton, Andrey I. Shukalyuk, and Dawn M. Kilkenny \\ Institute of Biomaterials and Biomedical Engineering, University of Toronto. \\ *These authors contributed equally to this work \\ dawn.kilkenny@utoronto.ca
}

\begin{abstract}
With the diverse nature of the biomedical engineering (BME) field, high school students are often limited in their understanding of the area during consideration for post-secondary study. In effort to improve student comprehension, as well as provide a unique learning opportunity in STEM (science, technology, engineering, and math) curriculum, graduate students at the Institute of Biomaterials and Biomedical Engineering (IBBME; University of Toronto) have developed and launched the IBBME Discovery Program. In strong collaboration with high school educators, graduate student instructors designed and executed activity- and designbased learning focused on applicable topics in BME aligned with Ontario high school science curriculum learning outcomes. Results from this pilot suggest strong student engagement in data-based experimental learning, and graduate student development in knowledge translation and activity design through collaboration. These results provide a strong foundation for program growth and quantitative assessment.
\end{abstract}

Keywords: high school outreach, STEM curriculum, biomedical engineering, graduate student teaching, integrated curriculum

\section{INTRODUCTION}

Biomedical engineering (BME) is a diverse field that requires application of engineering fundamentals within a biological/clinical context. This diversity is often limiting for high school students considering their area of postsecondary study, as they do not understand how traditional engineering concepts will allow them to succeed in the field of human health [1]. One strategy to overcome this lack of understanding is for students to be immersed in a STEM (science, technology, engineering, and math) curriculum, where they engage in real-world problem solving, internships, and/or capstone-type projects. The results of these types of studies suggest that high school students, when given opportunity and support, are able to successfully complete rigorous STEM programs [2].
However, other studies have shown that close examination of student characteristics reveal that those at STEM schools are not significantly improved compared to their peers, as no differences in participation rates in advanced sciences and mathematics were observed [3]. This suggests that academic background may be irrelevant given equal opportunity for immersive BME experiences.

Other studies have examined factors influencing high school students' career considerations [4]. College students reported that their decision to consider a STEM major was made during high school rather than at graduation; student interest was found to be the important consideration, followed by parental influence, earning potential, and teacher influence, respectively [4]. These findings strongly suggest introduction to these fields in a memorable manner during high school is vital if students are to be encouraged to pursue STEM fields, especially within engineering [5].

Many institutions support the idea that post-secondary engineering outreach programs are effective ways to expose high school students to engineering education, the design process, and career options in the field. Although this is one mechanism to immerse students in BME, it is becoming more apparent that there is prerequisite for engineers to help secondary teachers appreciate the basic engineering design process and to develop relevant STEM hands-on activities [6]. Further to this, the only formal programs that produced significant differences in student self-efficacy were semester-long and academically challenging, as opposed to activities such as field trips or singular class visits. The Young Scientist Program, a 9week long intensive summer program for minority students, was founded in 1991 by graduate students at the School of Medicine, Washington University in St Louis. This program was unique as graduate students organized, designed, and participated in the various facets of the program [7]. Importantly, formative data during an 8-year longitudinal study showed that the program stimulated improvement in high school student pursuit of STEM undergraduate degrees.

Supported by the outcomes of such identified studies, BME graduate student instructors at the Institute of Biomaterials and Biomedical Engineering (IBBME; 
University of Toronto) have developed and launched the IBBME Discovery Program, a collaborative high school science outreach program that stimulates application of STEM concepts within a unique year-long applied curriculum delivered within the high school and IBBME undergraduate teaching facility environments. The objective of the program is to provide high school science students within a cohort opportunities to engage in challenging practical BME activities as a mechanism to stimulate comprehension of STEM curriculum application to real world concepts. This program has been designed to introduce senior high school students to BME, in the context of the research occurring at IBBME, through a continued immersive educational experience. Further to this, the program is designed to provide IBBME graduate students, who represent members of the community of BME practice, the opportunity to engage in development and delivery of curriculum aligned to their specific thesis research theme(s). The high school students were given instruction through activity- and design-based learning, allowing the graduate student instructors to engage in and appreciate the benefits of building pedagogical skillsets. Through these experiences, high school students gained relevant learning tools as they progress towards postsecondary study and future careers.

\section{PROGRAM STRUCTURE}

\subsection{Program Goals}

Our approach focuses on collaboration with high school educators to develop specific teaching modules that align with the Ontario high school science curriculum (The Ontario curriculum, grades 11 and 12: Science, 2008) [8]. We collaborate with teachers to showcase the Institute's current research methods and innovations, and discuss trends in education. Furthermore, as a consequence of these collaborations, we prepared hands-on lesson plans suitable for STEM-focused school curriculum that are based on biomedical engineering problems. This pilot program is tailored towards students in Grades 11 and 12 that are involved in the science stream. Our primary goals are to expand high school student knowledge of key areas of biomedical research, ignite overall curiosity, and showcase the renowned research and facilities at the IBBME with the support of graduate student-led knowledge translation.

Mission Statement: Introduce high school students to current biomedical engineering research by creating an immersive educational experience around collaborative research themes.

Program student Learning Outcomes: (1) meet Ontario curriculum-specified course learning outcomes identified by educators; (2) connect course-scientific concepts to hands-on applications; (3) understand the collaborative nature of biomedical engineering and IBBME research themes (themes include: i) Biomaterials, Tissue Engineering \& Regenerative Medicine; ii) Engineering in a Clinical Setting; iii) Nanotechnology, Molecular Imaging \& Systems Biology; and iv) Neural, Sensory Systems \& Rehabilitation); (4) develop real-world translation of scientific principles; and (5) provide a platform for IBBME graduate students to develop pedagogical skills.

\subsection{Curriculum Development}

One of the goals of this program was to provide STEM opportunities to an entire class of high school students. Traditional outreach programs accomplish this for a cohort by either providing: i) a class tour of a BME laboratory or research facility; or ii) a demonstration or hands-on activity by a scientist/graduate student at the high school. Alternatively, outreach programs on university campuses exist but are not exclusive to a cohort, often drawing a mixed population of students at varied grade levels. In contrast, one of the overarching goals of the Discovery Program is to translate BME/STEM principles to a high school cohort in iterative fashion throughout the school year. Rather than approach student recruitment through these standard mechanisms, the method used in designing the Discovery Program was to approach school administrators (i.e., principal or department head) and recruit multiple science classes (students and their teachers) from within one school. The hypothesis was that a cohort-targeted approach supports the feeling of community within a school environment, and acceptance of time commitment as part of the classroom learning environment.

Emphasis was placed on developing a level of trust between high school educators and the IBBME-based organizing team. A fluid relationship between these parties from the onset of the program was anticipated to allow graduate instructors to work with individual teachers to personalize protocols and instruction strategies for their specific science class(es). Furthermore, this strategy allowed alignment of specific curriculum goals for each educator, as adaptable protocols were created that could be delivered on campus, but also integrated into ongoing lesson plans.

As a consequence of this integration, we hope to gain an understanding of how each teacher presents knowledge to their students and thus tailor our instruction accordingly. Curriculum delivery to a class cohort accompanied by their educator is unique to this program and is noticeably beneficial as it removes social barriers that can limit student learning and success. Students have the advantage of being surrounded by their peers and teachers while engaging in program components, and this translates to a level of comfort while working with graduate student 
instructors on complex scientific concepts as they learn and work with their peers. Established graduate instructor-high school educator relationships were similarly beneficial, as educators were willing to co-instruct within IBBME facilities.

The pilot year of this program was a collaboration of IBBME graduate instructors and educators from one Toronto District School Board high school. The school was a strong fit when considering the outreach aspect of this program, as average household income is less than $\$ 50,000$ per year with a large population of English as a second language students. Although these parameters gave additional challenge to program implementation, they served as a good model to understand potential for widespread enactment. At program onset, educators were introduced to current research methods and innovations at IBBME and, as a result of discussions of trends in education, instructors developed hands-on BME-based STEM lesson plans confirmed to align with the Grades 11 and 12 Ontario science curriculum. To validate incorporation of these activities within the high school curriculum, educators assigned $10 \%$ of their course grades to activity deliverables. During Phase One (Fall 2016), 60 students and 4 educators visited IBBME on three separate occasions. During each day-long visit, students engaged in activities that integrated biological, chemical and physical curriculum addressing a specific BME problem. Teaching methods included wet-bench laboratory work, design, and interactive facility tours. This learning style was activity focused, such that students worked on multiple concepts which varied during each visit. The activity structure resembled typical laboratory assignments conducted in their science classes. During Phase Two (Spring 2017), students were given an engineering design problem to assess, and were required to formulate recommendations based on data collection conducted in IBBME facilities. Students were assessed through activity deliverables and their involvement and engagement was assessed qualitatively as a method to discern future program redesign.

\subsection{Activity-based learning}

In Phase One of this pilot, Grade 11 and 12 students enrolled in university tract science visited the $U$ of $T$ campus (IBBME) on three separate occasions (7 hours per visit; 1 visit/month). During each visit, the students were divided into three groups and participated in wet-lab, design, and/or tour-based activities. These experiences were designed to directly link classroom curriculum to IBBME research themes, which showcase the diversity of BME. As a consequence of visits being full-day, students had opportunity to fully engage in biological wet-lab, computer-aided design, and tour based hospital settings (Table 1). The activities were designed to be interleaved, such that experiences in the wet-lab and CAD design prototyping suite constituted a half day schedule. This promoted retention of student interest and allowed student/teacher reflection on skills learned during the session, developing more efficient application during the subsequent visits. To support these activities, graduate student instructors visited the high school classroom one week in advance of each campus visit to introduce important experimental concepts. This allowed students to familiarize themselves with the experimental plan and prepare any necessary pre-laboratory material prior to practical activities at IBBME. It should be noted that although students were identified as being enrolled in a specific science class (i.e., Grade 11 Biology), they were exposed to all activities during Phase One, irrelevant of focus on biology, chemistry, or physics. This design strategy allowed for learning opportunities of the different facets of BME, as well as the growing of reality that science is inter-disciplinary and does not typically fall under a single discipline.

Table 1: Summary of activities in program Phase One.

\begin{tabular}{|l|l|l|}
\hline \multicolumn{1}{|c|}{ Activity } & $\begin{array}{l}\text { IBBME } \\
\text { Facility }\end{array}$ & Key Scientific Content \\
\hline $\begin{array}{l}\text { Bransfection } \\
\text { Teaching } \\
\text { Lab }\end{array}$ & $\begin{array}{l}\text { Transfection of } \text {. coli } \\
\text { using plasmids for } \\
\text { green fluorescent } \\
\text { protein expression }\end{array}$ \\
\hline $\begin{array}{l}\text { Biomaterial } \\
\text { Assessment }\end{array}$ & $\begin{array}{l}\text { Teaching } \\
\text { Lab }\end{array}$ & $\begin{array}{l}\text { Characterization of } \\
\text { material properties for } \\
\text { common biomedical } \\
\text { materials }\end{array}$ \\
\hline $\begin{array}{l}\text { LEGO } \\
\text { Modelling }\end{array}$ & $\begin{array}{l}\text { Design } \\
\text { Studio }\end{array}$ & $\begin{array}{l}\text { Introduction to CAD } \\
\text { modelling with } \\
\text { dimensioning and } \\
\text { drawing LEGO }\end{array}$ \\
\hline $\begin{array}{l}\text { Minimally block } \\
\text { invasive tool } \\
\text { design }\end{array}$ & $\begin{array}{l}\text { Design } \\
\text { Studio }\end{array}$ & $\begin{array}{l}\text { Practical medical device } \\
\text { design for pseudo } \\
\text { surgical removal of } \\
\text { tumor phantom }\end{array}$ \\
\hline $\begin{array}{l}\text { Toronto } \\
\text { Rehabilitation } \\
\text { Institute (TRI) } \\
\text { Tour }\end{array}$ & $\begin{array}{l}\text { Hospital } \\
\text { Site }\end{array}$ & $\begin{array}{l}\text { Understanding the role } \\
\text { of rehabilitation in a } \\
\text { hospital setting for } \\
\text { injury recovery and } \\
\text { prevention. }\end{array}$ \\
\hline
\end{tabular}

Wet-lab based activities focused on the concepts of traditional BME, including biomaterials and bacterial transfection. Students had opportunity to work with stateof-the-art equipment at the IBBME Undergraduate Teaching Laboratory (http://www.ibbme.utoronto.ca/). This was a stark change from the biological lab space at the high school which offers limited resources for experiential science. To understand the impact of material properties, they assessed the physical characteristics of different biomaterials. In their first exposure to cell culture, students 
performed transfection of Escherichia coli for visualization of antibiotic resistance. All students, independent of the science course in which they were enrolled, were required to write a lab report as the deliverable for each of these activities. These reports contained both general discussion questions as well as course-specific questions. Such a structure allows for assessment of student comprehension of the experimental topic in relation to the content of the varied science curricula (i.e., perception of biology students compared to physics students). This deliverable posed an intellectual challenge for the students as they had to generate a complete laboratory report, but also apply scientific concepts to material beyond course content.

In the IBBME Design Studio facilities (Collaboration Suite and Fabrication \& Prototyping Suite) students were taught how to use SolidWorks ${ }^{\circledR}$ (CAD design) to draw for three-dimensional (3D) printing. The students were given the initial task of dimensioning and drawing a standard LEGO $^{\circledR}$ brick for development of a 3D printed structure to scale. Consequently, these skills were transferred to a practical engineering problem in the design of a simplified minimally invasive surgical tool. Specifically, the students were asked to create a hook for removal of an object from an ex vivo brain model (Figure 1). The students were asked to consider: (1) ability of the hook to capture the object (an elastic band) embedded within the organ; and (2) minimize damage to the surrounding brain tissue upon object removal from the brain. CAD designs were $3 \mathrm{D}$ printed and attached to handles, and students subsequently attempted 'surgery' on gelatin brain models. This activity was designed for exposure to conceptual design with tangible feedback on the appropriateness of the work.

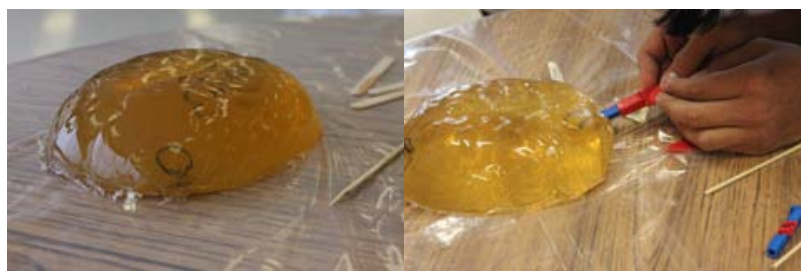

Figure 1: Pseudo gelatin brains were used to model minimally invasive surgery with $3 \mathrm{D}$ printed hooks.

Finally, to support student comprehension of BME in the clinical setting, visiting classes were taken on a tour of the cutting edge facilities at the Toronto Rehabilitation Institute. This provided an opportunity to observe and inquire about the role of engineering in supporting rehabilitation from, and prevention of, injury or disease. Furthermore, a gentleman in the facility described his experience as a patient in rehabilitation post-injury, and hosted a short question and answer session. This provided a very unique perspective of the role of rehabilitation in recovery, but also the overall translation of STEM. Once this activity was complete, students were asked to reflect on the role of rehabilitation in the general population in the form of an essay, thereby creating an opportunity to think about the societal impact of BME in healthcare.

\subsection{Project-based learning}

Reflections on the deployment and outcomes of Phase One led to the design of Phase Two as a project-based learning experience in this program pilot. This was based on the highly positive student feedback in response to the brain surgery tool design component of Phase One, which suggested that this BME design experience was a unique opportunity for these students. Consequently, instructors and educators agreed to re-structure the second term to mimic a typical engineering capstone design, where student research teams work with a client to propose a problem solution (Figure 2). Still ongoing at the time of this conference, small student groups are working together in a capstone format to address a discipline-specific request for proposal (RFP) on a common theme (prosthetics). Rather than focusing on typical written assessment, Phase Two will culminate in a final oral symposium at IBBME. This will increase the novelty of the experience for students, as they will present their proposals in research poster format to graduate and undergraduate students. It is expected that this will encourage students to think critically about their recommendations to the problem in the context of their science curriculum (i.e., from either a biology, chemistry, or physics perspective).

\section{Prosthetics For Amputees}

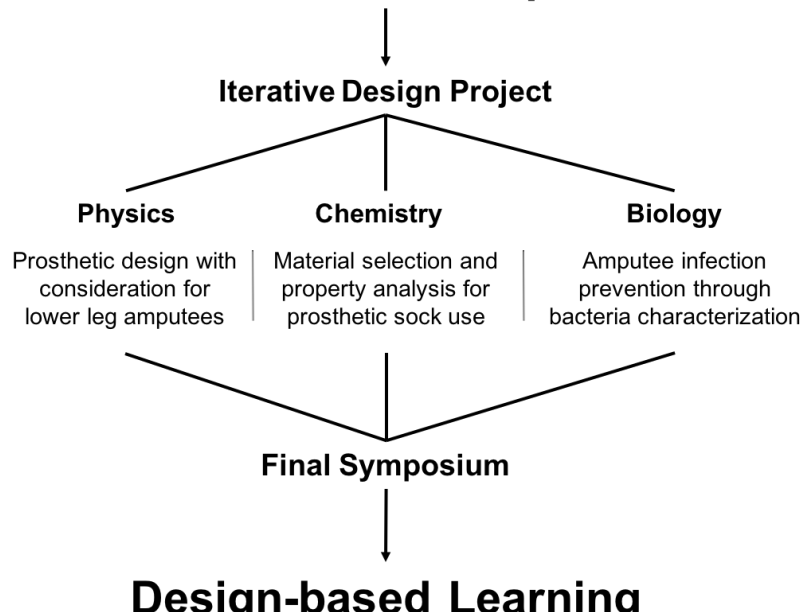

Figure 2: Summary of design-based learning projects executed in Phase Two.

Given that the students gained familiarity with the graduate instructors and IBBME facilities during Phase One, they were disassembled from the class cohort format during this second phase of the project. Small student groups were formed following the theme of BME in prosthetic development. Also in contrast to the Phase One 
experience, students did not participate in design related to all STEM subjects. Rather, three individual sub-topics were selected to ensure relevance to the specific class subject area. This format was suggested by high school educators to ensure that students not only had a foundation to propose laboratory methods and analyze results, but that curriculum content was addressed. The subtopics selected in relation to each subject were: (1) characterization of resistant bacteria for amputee wound treatment (biology); (2) soft material properties for contact surfaces between patient and prosthetic (chemistry); and (3) engineering and dynamic modelling of a lower limb prosthetic (physics). Although the initial research questions offered a significant degree of ambiguity, design was narrowed in focus by available laboratory inventory and student knowledge level.

Students were encouraged to give intelligent experimental design and consider the approach they would like to take in assessing the research question. This ideation was submitted as a proposal document by each group for review by graduate student instructors. Individual teams were consequently assigned to a specific graduate student instructor to allow for continuity in recommendations throughout the experience. Proposals were presented in a client meeting format in the high school classrooms, allowing graduate students to narrow the approach of each design in advance of the experimental visits to IBBME facilities. Two day-long visits were scheduled on campus to allow teams opportunity to experimentally approach their studies. These visits were scheduled two weeks apart to allow time for assessment of preliminary results, and planning for additional experiments during the second visit. The third visit to campus was designed to occur several weeks later, allowing the groups time to disseminate their findings in the form of a scientific research poster. The student experience will culminate with presentation of posters to peers and undergraduate summer research students in symposium format, supported by the addition of a faculty keynote speaker whose research is in the area of prosthetics and clinical engineering.

\subsection{Professional development for graduate students}

This program was founded by graduate students at the IBBME, and is fully supported by IBBME faculty and staff. These graduate students represent members of the community of BME practice and have expressed a dedicated interest in the practice of engineering education that extends beyond supervision of undergraduate students during their thesis experience, or participation in BME courses as a teaching assistant. These graduate instructors oversee all program communication and curricular components; program structure has allowed the graduate instructors continued exposure to curriculum development and deployment as well as program administration. To fulfill the program requirement of showcasing the diversity of BME, at least one student representative working within each IBBME research theme participates as 'theme lead' within this program. These theme leads, in association with the overall program coordinator (a doctoral thesis student), form the program's leadership team. This format ensures different BME topics are represented in the direction and development taken by the steering committee. Collectively, this student team forms the foundation of the program structure.

The leadership team has communicated directly and extensively with high school educators and administration throughout the school year since initial outreach to establish a professional working relationship. This program capitalizes on the fact that the educators have extensive training in the best methods to instruct high school students, but also the experience of interacting daily with their student cohorts. Importantly, this program is structured such that the responsibility of assessment and instructional methods remains with the school staff. This has necessitated significant coordination of graduate student instructors and educators; however, educator feedback and iteration of activity structure has led to the framework for adaptations of teaching strategies. Furthermore, graduate students are not often exposed to the processes of funding acquisition for developing a new program that is representative of an institution in the public eye. For the leadership team, this structure allows for direct interaction with faculty to gain valuable information about the navigation of these endeavors.

The leadership team only makes up a small percentage of the committed graduate students involved in this program. Over 20 volunteers have been involved at lower frequency throughout the year to ensure safe and smooth operation of activities. These volunteers have participated in asking high school students engaging questions, and in Phase Two took a hands-on leadership role when interacting with student 'capstone' teams. Beyond the leadership team, graduate student instructors gain valuable insight into instruction and knowledge translation. Although a lot is said about the concepts of knowledge translation in the field of BME, the Discovery Program provides graduate instructors an opportunity to instruct concepts from their own thesis research to the general population. These are skills that hold high value in academia and industry. Furthermore, the teaching skills developed are directly transferrable to sessional teaching positions (such as Teaching Assistantships or lecturers) or future career roles (in academia or otherwise). Training for graduate student teachers is often limited therefore opportunities such as those available through this program hold high value for those graduate students interested in expanding their pedagogical skillset. In addition, this program will give IBBME students improved chances to receive training grants and scholarships, and ultimately 
make them more marketable when moving forward to their next endeavors.

\section{RESULTS AND DISCUSSION}

Qualitative observation over the first eight months of this program demonstrated noticeable benefits to involved parties. We believe that curriculum delivery in an iterative manner throughout the school year to a class cohort accompanied by their educator is unique to this program and is noticeably beneficial as it removes social barriers that can limit student learning and success. Students were engaged in activities immediately upon arrival at the campus/IBBME facilities, and were therefore removed from the awkward environment that often arises when students from several schools and classes are brought together for experiential learning (i.e, summer camp). It is our opinion that this outcome helped to foster an environment where students felt they could interact with each other and the graduate student instructors to make relevant queries and build a solid understanding of the task at hand. Further to this, the students demonstrated excitement and attentiveness when on site, constantly asking graduate students about the science they were learning, as well as engaging in inquisitive discussion surrounding BME and potential post-secondary education opportunities.

These interactions were observed to blossom during the students' second and third program days, and were prominent at the start of Phase Two, as their comfort with instructors and laboratory environments increased. This aspect of the program once again provided further benefit, as the novelty of the experience of a new location was replaced with the excitement of scientific discovery. Similarly, high school educators identified that all students engaged in the various activities, arriving at the IBBME on time with near perfect cohort attendance and excitement to participate; this is considered one indicator of program success as these educators had previously identified difficulties with student involvement in the regular classroom. Participation carried over to completion of required deliverables: educators believe that their students took a sense of pride in their involvement in this program, understanding the unique opportunity in being involved with graduate student and university facilities, thereby taking full advantage of knowledge acquisition.

Established graduate instructor-high school educator relationships were similarly beneficial, as educators were willing to co-instruct within IBBME facilities. These relationships allowed the construction of activities to thrive, incorporating instruction techniques to ensure difficult students were involved in the activities rather than distracting their peers. It was feedback from these educators that led to the change in pedagogical structure for Phase Two of the curriculum. Educators felt that working through the design process and analyzing critical data are not easily accomplished in the classroom setting. Education often falls into the articulated milestones within the government mandated curriculum, which guides educators in the content they are to deliver to students. Therefore, because of limited time and resources, students often are engaged in lab activities focused on curriculum content rather than the scientific process and data analytics. Currently ongoing, the impact and outcomes of this altered learning strategy are being investigated. Preliminary observations suggest that despite being comfortable in the IBBME laboratory setting, the students have been pulled out of their comfort zone while working in small groups to develop scientific methods. Herein, groups are not expected to excel in establishing a thorough and accurate experimental design in the first attempt, as this would not be reasonable given their level of experience. Rather, it is the expectation that this unique opportunity to iterate with a graduate student instructor during the semester will support independent thinking and teamwork to develop an experimental process and formulate recommendations given an inventory of possibilities. Furthermore, a partnership was formed with the IBBME Undergraduate Summer Research Program, where undergraduate students have agreed to attend the final symposium and interact with students about their projects. This should allow another unique interaction for high school students as they explain their final recommendations at the final symposium.

Importantly, the involvement of graduate instructors in the development and teaching process was observed to improve their methods of interaction with students, suggesting engagement in this program provides valuable teaching opportunities for our graduate students. Volunteer retention from Phase One to Phase Two was 85\%, suggesting graduate participants found involvement to be both rewarding and of value to professional development. A number of the participating graduate students hold teaching assistant positions, and those that do not intend to pursue these alternate opportunities in the future. Skills gained through the Discovery Program will hold high value in their educating roles. Knowledge translation to a high school learning level by instructors has been essential to program success, and the opportunity to interact with educators enhanced these skillsets, including communication and comfort level with students. Although the pilot is still ongoing, we have begun to consider how the program will continue to grow. Building on the foundation of experiential learning through engineering design, we hope to grow to a larger student body to instill skills of data based learning.

\section{NEXT STEPS}

Given the qualitative success observed in this pilot year, we are looking to move forward with both quantification of first year program success, as well as growth and sustainability. Written assignments will be used to 
quantitatively assess student comprehension, and all participants will complete a survey structured to assess activity learning outcomes. Blinded numerical grade averages for the activity deliverables in each phase will be compared to course grades for students. We will also quantify the observations made with respect to student attendance and participation through attendance records and project completion.

We believe that the Phase Two activity model is sustainable in expansion of the program, as it does not necessitate complex activity planning but rather the development of a design theme. With expansion to multiple schools, the final symposium could involve the interaction of a number of school groups who have made designs according to a common BME-relevant theme. This program has been built on the development of partnerships, and for sustainable expansion to be possible, we look to utilize development of strong professional relationships. In partnering with other schools, we will first link with supportive administration to facilitate the development of a strong partnership.

Finally, it is important that we work to build the program to support graduate student instructors. To ensure their hard work is recognized, we will investigate a method of formal recognition. With this, it is our hope that we can formalize the training for instructors and the relevant transfer of skills to other educational roles.

\section{CONCLUSIONS}

With the motivation to demonstrate the role of BME in healthcare to high school students, graduate students from the IBBME at University of Toronto developed the IBBME Discovery Program. Balancing the needs of the Ontario high school curriculum learning outcomes with course specific content, visiting high school students engaged in scientific activities with real world prevalence. Uniquely, this program was developed through strong professional collaborations between high school educators and graduate student instructors, who worked together to share the load of activity instruction and development to optimize the involvement of their individual expertise. This provided a foundation to the development of pedagogical skills for the graduate students involved, further contributing to the growth of the professional skills.

Qualitatively, participating high school students demonstrated high enthusiasm and inquisition to learning in this program, indicated by high attendance and deliverable completion. This involvement, in association with strong working relationships with peers and graduate student mentors, allowed students to reach out of their comfort zone in a design based project of BME relevance, exposing them to data based experimental design. As this program continues to grow, we look to rely on these principles of collaboration and BME to provide students a foundation to inquisition through the scientific method.

\section{Acknowledgements}

The authors would like to acknowledge the support of the graduate student volunteers from the Institute of Biomaterials and Biomedical Engineering for their countless hours of support in program planning and execution; the science department at George Harvey Collegiate Institute for help in program development and execution, as well as their administration for support; and the support of the IBBME Director and Undergraduate Programs office. This program was financially supported by the IBBME.

\section{References}

[1] M. J. S. Dr. Mansoor Nasir, Dr. Eric G Meyer, "Introducing High School Students to Biomedical Engineering through Summer Camps," in 2014 ASEE Annual Conference \& Exposition, Indianapolis, Indiana, 2014, p. 15.

[2] C. Scott, "An investigation of science, technology, engineering and mathematics (STEM) focused high schools in the US," Journal of STEM Education: Innovations and Research, vol. 13, p. 30, 2012.

[3] M. Wiswall, L. Stiefel, A. E. Schwartz, and J. Boccardo, "Does attending a STEM high school improve student performance? Evidence from New York City," Economics of Education Review, vol. 40, pp. 93-105, 2014.

[4] C. Hall, J. Dickerson, D. Batts, P. Kauffmann, and M. Bosse, "Are we missing opportunities to encourage interest in STEM fields?," 2011.

[5] P. M. Sadler, G. Sonnert, Z. Hazari, and R. Tai, "Stability and volatility of STEM career interest in high school: A gender study," Science Education, vol. 96, pp. 411-427, 2012.

[6] P. A. Ralston, J. L. Hieb, and G. Rivoli, "Partnerships and experience in building STEM pipelines," Journal of Professional Issues in Engineering Education and Practice, vol. 139, pp. 156-162, 2012.

[7] K. B. Chiappinelli, B. L. Moss, D. S. Lenz, N. A. Tonge, A. Joyce, G. E. Holt, et al., "Evaluation to Improve a High School Summer Science Outreach Program," Journal of microbiology \& biology education, vol. 17, p. 225, 2016.

[8] "The Ontario Curriculum Grades 11 and 12: Science," ed, 2008. 